\title{
Um Presente de Apolo: lasers, história e aplicações*
}

\author{
A gift from Apollo: lasers, history, applications
}

\author{
Climério Paulo da Silva Neto ${ }^{\dagger 1}$, Olival Freire Júnior ${ }^{2}$ \\ ${ }^{1}$ Universidade Federal do Oeste da Bahia, Barra, BA, Brasil \\ ${ }^{2}$ Universidade Federal da Bahia, Salvador, BA, Brasil
}

Recebido em 11 de julho de 2016. Revisado em 3 de agosto de 2016. Aceito em 9 de agosto de 2016

Lasers definitivamente revolucionaram a ciência e sociedade em que vivemos e, portanto, merecem espaço nas salas de aulas de física. Este artigo apresenta uma breve discussão histórica e conceitual sobre a invenção do maser e do laser que pode ser utilizada no ensino médio e permite discutir tanto o princípio de funcionamento e as principais características de lasers, como monocromaticidade e coerência, quanto aspectos da relação entre ciência e sociedade no século XX, em especial sobre a influência das duas grandes guerras mundiais e da Guerra Fria na física. Além disso, são elencados os principais fatores que levaram à invenção do maser nos Estados Unidos e na União Soviética, quase que simultaneamente, e que estimularam o desenvolvimento de lasers nas principais potências da Guerra Fria e também no Brasil na década de 1960. Tanto a importância de ensinar física moderna no ensino médio quanto a importância da história das ciências como forma de discutir questões relativas à natureza das ciências e à relação das ciências com política e sociedade tem há muito sido enfatizada por pesquisadores em ensino de ciências, ênfase que foi incorporada à proposta da Base Nacional Curricular Comum que vem sendo elaborada pelo Ministério da Educação.

Palavras-chave: Lasers; História do Laser; Física na Guerra Fria.

Lasers definitely transformed science and the society in which we live. Thus, they no doubt deserve space in physics classrooms. This article presents a brief historical and conceptual discussion on the invention of masers and lasers that may be used in physics classrooms of secondary schools and allows to discuss the working principle of masers and lasers, key concepts such as coherence and monochromaticity, as well as aspects of the dynamics between science, technology and society in the 20th century, in especial the impact of the two major World Wars and the Cold War on Physics. It also presents some of the main factor that led to the invention of masers in the United States and the Soviet Union, almost simultaneously, and that fostered the development of lasers in the major powers of the Cold War and Brazil in the 1960s.

Keywords: Lasers; History of Lasers; Physics in Cold War.

\section{Introdução}

Apolo é uma das divindades mais complexas e versáteis do panteão grego-romano. Ele era considerado o Deus da luz, conhecimento, medicina e cura, música, artes e mais. A luz Laser, de forma semelhante,

\footnotetext{
${ }^{*}$ Este artigo foi escrito com base na tese de doutorado de Climério P. da Silva Neto, sobre a história do laser na União Soviética, que contou com apoio financeiro da CAPES, do American Institute of Physics e da University of British Columbia.

${ }^{\dagger}$ Endereço de correspondência: climerio.silva@ufob.edu.br
}

revelou-se uma ferramenta extremamente versátil, frequentemente chamada de "a luz de mil funções", ou de "uma solução em busca de problemas". Desta forma, o paralelo entre laser e Apolo não é restrito ao fato de Ele ter sido considerado o Deus da luz. Lasers têm desempenhado muitas das funções que eram atribuídas ao Apolo pelos gregos. Eles têm revelado novos conhecimentos em diversos ramos das ciências. Campos como ótica não-linear e ótica quântica foram criados a partir do estudo de lasers e suas propriedades, ou de aplicações de lasers para estudar e elucidar alguns fenômenos já conhecidos, 
mas que eram pouco compreendidos pelos físicos. Lasers encontraram uma ampla gama de aplicações em diagnoses, tratamentos e terapias médicas, sendo também utilizados como ferramentas em procedimentos que vão desde cirurgias, onde são utilizados como bisturi, até cicatrização de ferimentos. Além disso, o compositor, artista de performance e produtor francês Jean Michel Jarre já encantou milhões de pessoas com displays musicais de lasers e sua harpa laser que são as grandes atrações de seus concertos desde 1981. São verdadeiras obras de arte contemporânea. E basta apenas digitar em uma ferramenta de busca "laser art" para ver diversas obras de arte baseadas em lasers ou feitas com lasers. Eu poderia continuar apresentando muitas outras conexões entre Apolo e lasers, mas eu vou apresentar apenas mais uma: Apolo é frequentemente representado com uma harpa ou com um arco com uma flecha que é um raio de luz, o que é a mais remota representação de uma arma de energia direcionada, que atualmente são lasers de potências altíssimas.

O que é esse presente divino que permite tantas possibilidades e aplicações? É isso que veremos aqui. Pode-se dizer que o presente não é o laser em si, mas a habilidade de domar dois efeitos quânticos chamados de emissão espontânea e emissão estimulada de radiação. O nome laser é, na verdade, uma sigla para a expressão inglesa Light Amplification by Stimulated Emission of Radiation. Em português: Amplificação de Luz por Emissão Estimulada de Radiação. Isto quer dizer que a ação mais básica do laser, o que o laser faz, é amplificar luz usando o efeito de emissão estimulada de radiação 1

Vejamos então o que é esse fenômeno chamado emissão estimulada, estudando um pouco de física. Apesar de o laser só ter sido inventado em 1960, a física de seu princípio de funcionamento foi desenvolvida nas duas primeiras décadas do século XX com o desenvolvimento de uma teoria chamada mecânica quântica, ou teoria quântica. Um dos pais fundadores da teoria quântica, o físico que recrutou jovens físicos para construir aquela teoria, foi um dinamarquês chamado Niels Bohr.

A Dinamarca é um país muito pequeno do norte da Europa, que era quase insignificante na física até aquela época, mas que foi muito beneficiada pelo clima hostil entre países europeus durante e depois da Primeira Guerra Mundial. Antes de ci-

\footnotetext{
${ }^{1}$ Dois outros artigos interessantes que permitem discutir lasers e física moderna no ensino médio são 1] e 2 .
}

entistas, físicos são seres humanos, vulneráveis às mesmas paixões, medos e inquietações que todos os outros. Apesar de a ciência buscar ser, e se dizer ser, imparcial, independente de política, religião e outras formas de ideologia, ela mais frequentemente não é. Isto é claro na história da física no século XX e também na história do laser, como veremos adiante 2

Durante a Primeira Guerra Mundial a física $\mathrm{Eu}-$ ropeia se dividiu em campos hostis. Físicos de um campo cortaram quase todos os laços com os físicos do outro campo. A Dinamarca foi um dos poucos países que permaneceram neutros durante a guerra e com isso Bohr pôde manter laços com físicos dos dois campos [5]. O seu instituto na Dinamarca tornou-se um lugar onde os físicos das nações envolvidas na guerra, mas que não se envolveram tão fortemente com os sentimentos nacionalistas, podiam interagir e cooperar para o desenvolvimento da física do que ficou conhecido como o modelo atômico de Bohr. A Dinamarca também foi um dos poucos países que não foram afetados por uma grave crise econômica e pôde dar o suporte necessário para convidar jovens talentos, que estavam passando por sérias dificuldades financeiras em seus países, para trabalhar no instituto de Bohr. O desenvolvimento da teoria quântica naquelas condições teve várias implicações interessantes porque mostra como o contexto cultural pode influenciar a forma até mesmo das teorias mais bem-sucedidas da física [6,7]. Mas isso é assunto para um outro momento. $3^{3}$

Voltando à teoria quântica, de acordo com seu princípio mais básico, sistemas atômicos e moleculares têm níveis de energia quantizados e bem definidos, daí o nome teoria quântica. Em um átomo, por exemplo, um elétron pode ocupar apenas certos orbitais associados com níveis bem definidos de energia (Figura 1). Para mudar de um orbital para outro, um elétron tem que absorver ou emitir energia, para dar um salto quântico, porque a região entre os níveis de energia é um território proibido de acordo

\footnotetext{
${ }^{2}$ Tanto a importância de ensinar física moderna no ensino médio quanto a importância da história das ciências como forma de discutir questões relativas à natureza das ciências e à relação das ciências com política e sociedade tem há muito sido enfatizada por pesquisadores em ensino de ciências, 3] ênfase que foi incorporada à proposta da Base Nacional Curricular Comum que vem sendo elaborada pelo Ministério da Educação. 4

${ }^{3}$ Esses episódios são discutidos de maneira lúdica em um jogo pensado para discutir natureza das ciências que é apresentado em 8.
} 


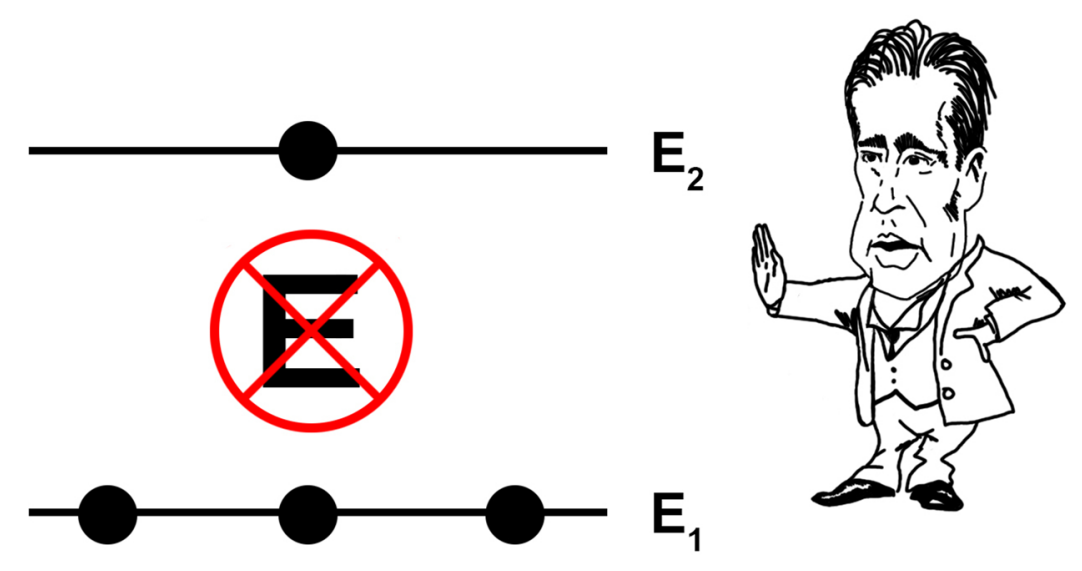

Figura 1: Segundo as leis do modelo atômico de Bohr, elétrons, representados de maneira não realística pelas bolinhas pretas, só podem ocupar níveis bem definidos de energia, na figura, representados por $E_{1}$ e $E_{2}$. Ilustração de Daria Chusovitina

com as leis da teoria. Para mudar para um orbital de energia maior, o elétron tem que absorver energia (Figura 2); para mudar para um orbital de energia menor, o elétron deve emitir energia. O mesmo é válido para outros sistemas quânticos. Moléculas, por exemplo, possuem níveis bem definidos de energia associados à rotações e vibrações de seus átomos e a transição de um nível para outro ocorre com emissão ou absorção de radiação, geralmente microondas ou infravermelho.

A explicação do efeito de emissão estimulada foi dada por Albert Einstein em 1917 [9]. Quando os elétrons em um átomo estão no estado de maior energia, conhecido também como estado excitado, eles podem mudar para o estado de menor energia de duas maneiras. Eles podem emitir energia espontaneamente, ou eles podem ser estimulados a emitir radiação e mudar para o estado de menor energia.

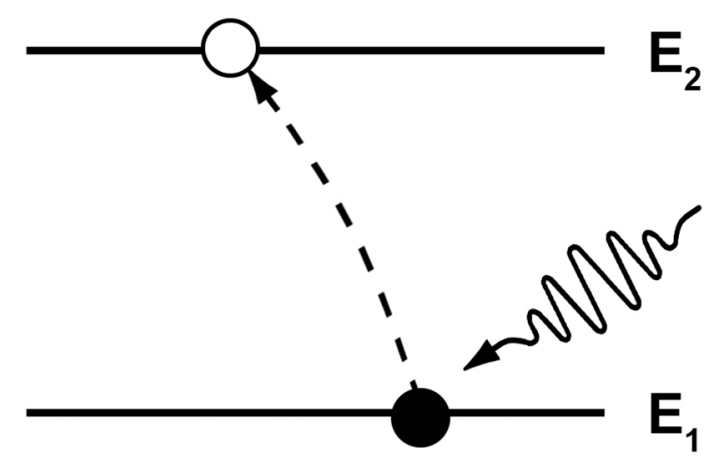

Figura 2: Quando um elétron é atingido por um fóton, representado pela onda-seta na figura, ele pode mudar do nível de energia $E_{1}$ para $E_{2}$, basta que o fóton tenha energia equivalente à diferença $E_{2}-E_{1}$.
Emissão espontânea ocorre naturalmente, porque o estado excitado é instável, e depois de um tempo, chamado de tempo de relaxação, o elétron decai espontaneamente, emitindo um fóton de radiação. Em algumas situações, entretanto, o tempo de relaxação é demasiadamente longo e é necessário estimular a emissão recorrendo ao efeito de emissão estimulada. A forma mais simples de fazer isso é irradiando o elétron com radiação de frequência equivalente à transição desejada (Figura 3).

A "Eureka", ou grande sacada, por trás da invenção do laser foi a compreensão de que se conseguirmos obter um meio no qual a maior parte dos átomos estão no estado excitado emissão espontânea e estimulada poderiam ser usadas para criar um feixe de luz poderoso, no qual todos os fótons têm praticamente a mesma frequência e oscilam em fase uns com os outros, o que os físicos chamam de um feixe de luz monocromático e coerente. São essas características do laser, a monocromaticidade, o que quer dizer que ele tem uma única cor, e a coerência, o que quer dizer que todos os fótons estão sincronizados, como um exército marchando em perfeita harmonia, que permitem fazer tantas coisas com laser.

Você sabe como é composta a luz do sol, ou luz branca? Ela é composta de todas as cores do arco-íris e pode ser separada com a ajuda de um prisma, mas a luz laser, em contraste, tem uma única cor. O que determina a cor é a frequência da radiação (quantas vezes a onda oscila por segundo). A luz vermelha possui menor frequência, que vai aumentando até chegar à violeta, que possui a maior frequência do espectro visível (Figura 4). À frequência também 

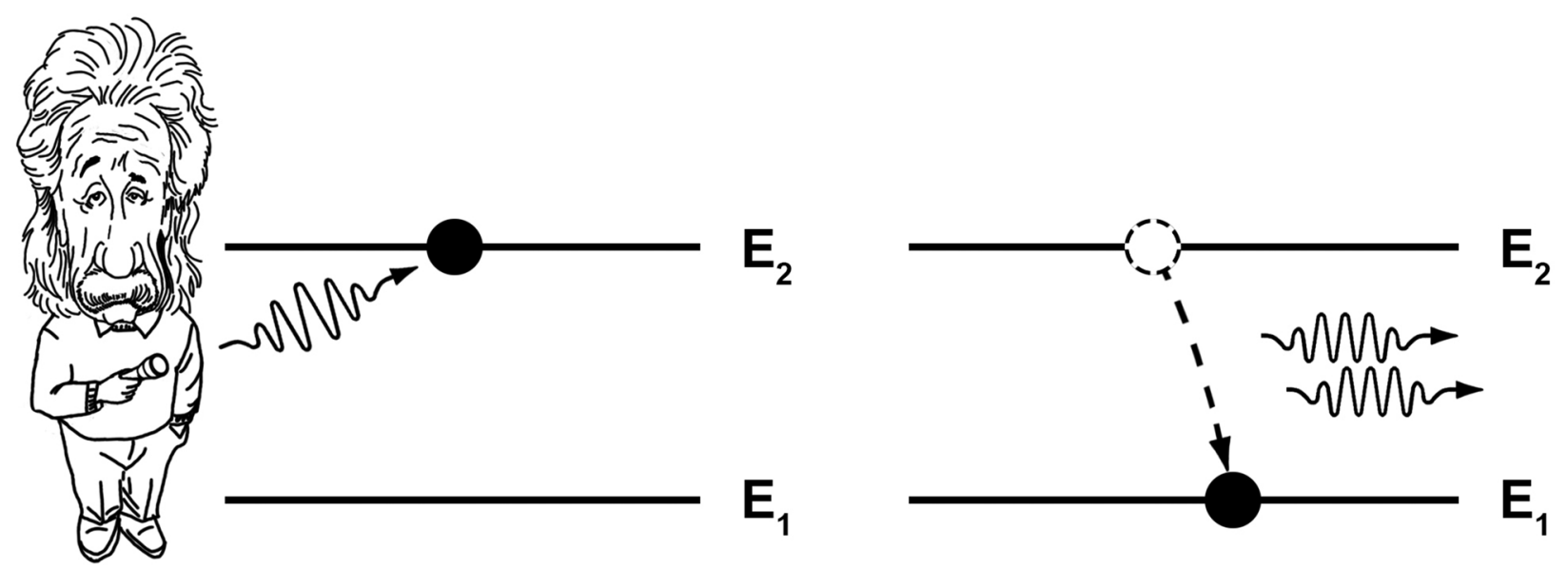

Figura 3: Quando um fóton atinge um elétron no estado excitado $E_{2}$ ele estimula aquele elétron a emitir um outro fóton e mudar para o estado $E_{1}$. Ilustração de Daria Chusovitina.

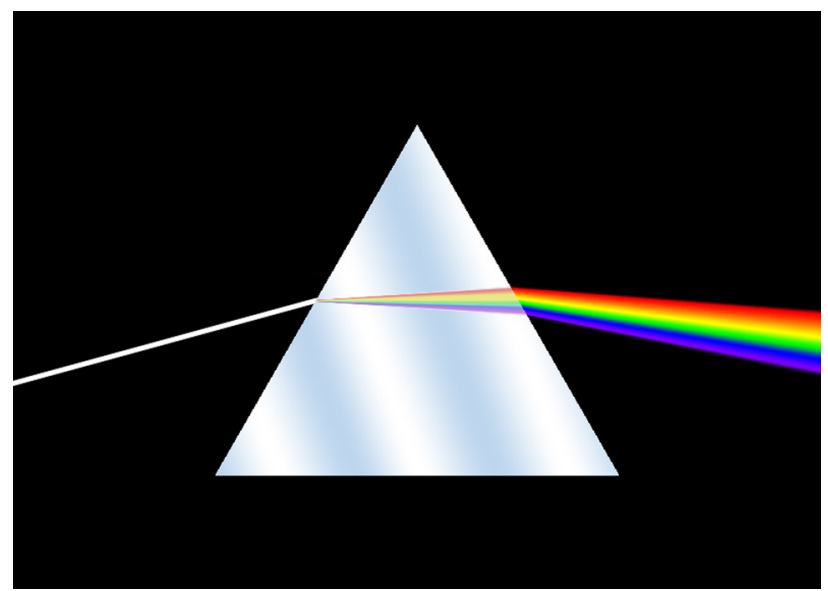

Figura 4: Luz decomposta em um prisma. A luz branca pode ser separada em luz de todas as cores do arco-íris, que diferem entre si pela frequência da radiação. A luz vermelha tem a menor frequência e a violeta tem a maior. Nesta figura, frequência aumenta de cima para baixo. Fonte: Wikimedia Commons.

está associada a energia da radiação, sendo que quanto maior a frequência, menor a energia. Assim, podemos dizer que lasers vermelhos têm energia menor do que os verdes, duas cores comumente encontradas em lojas de eletrônicos. O laser violeta é o que possui a maior energia dentre os lasers visíveis.

A coerência do laser é provavelmente sua característica mais excepcional. Voltando à analogia com o exército. Imaginem que o exército está fazendo uma apresentação no desfile da independência e resolve surpreender o público que está olhando das sacadas de prédios formando figuras, a bandeira do Brasil, por exemplo, com a formação dos soldados.
Se eles estiverem marchando de forma bem organizada, coerente, eles consequentemente formarão figuras bem delimitadas, bem desenhadas, mas se eles não estiverem bem organizados, estiverem pouco coerente, as pessoas olhando das sacadas terão dificuldade em reconhecer o que o batalhão está fazendo e possivelmente acharão que os soldados beberam antes do desfile. Comparando padrões de interferência de um laser, uma luz bem coerente, e com a luz branca, pouco coerente, podemos ter uma ideia do papel da coerência na formação de imagens. permitem criar figuras de interferência bem detalhados, de alta resolução (Figura 5), enquanto que a luz branca gera figuras de interferência com resolução bem mais limitadas, que possuem poucos detalhes. Alem disso, como luz de frequência diferente é difratada de forma ligeiramente diferente, imagens de difração com luz branca forma padrões sobrepostos de cores diferentes.

Uma terceira característica do laser que o distingue da luz comum é potência que pode ser alcançada com eles. A potência de um laser pode superar milhares de vezes a potência da lâmpada de flash mais potente que se conhece. Para se ter uma ideia de quão poderoso o processo de amplificação por emissão estimulada pode ser, imaginem uma montagem em um laboratório que é basicamente um meio, material, onde todos os átomos estão no estado excitado, colocado entre dois espelhos paralelos que estão separados por uma distância de um metro. Uma vez que o primeiro fóton é emitido, ele estimula a emissão de outros fótons, que por sua vez estimulam a emissão de mais fótons, que estimulam a emissão de ainda mais fótons e assim por diante. 


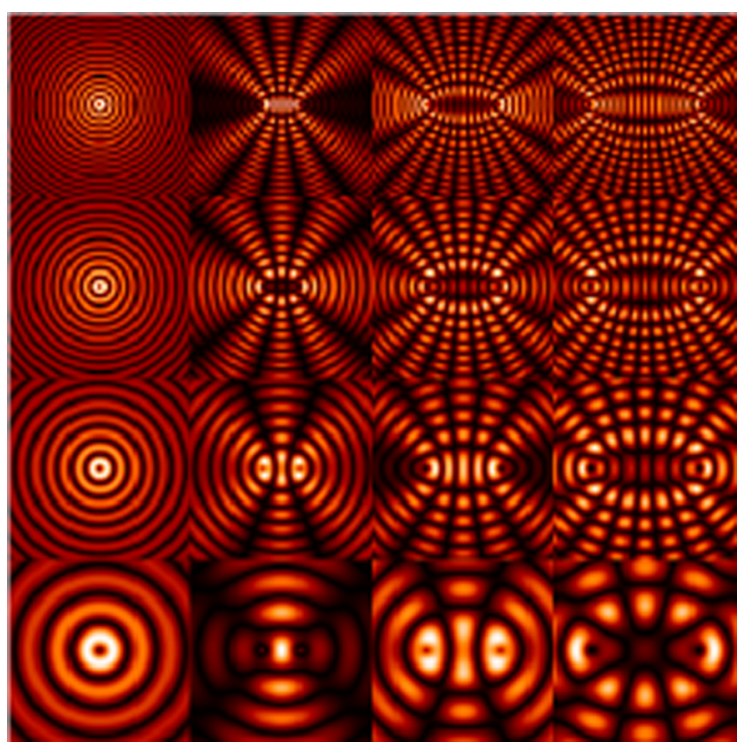

Figura 5: Padrões de interferência que o laser permite formar, graças à coerência. A luz branca permitiria formar apenas imagens coloridas borradas. Fonte: Wikimedia Commons.

Uma reação em cadeia acontece e o número de fótons cresce exponencialmente. Mas isto não é tudo. Se os espelhos são de qualidade, cada vez que a luz é refletida em um espelho, e retorna para o meio material, ela continua aquele processo e sua intensidade aumenta. Como a luz se move em uma velocidade muito alta, em um segundo ela percorre o espaço entre os espelho aproximadamente 300 milhões de vezes! O que quer dizer que não importa o quão pequeno é o ganho de intensidade de radiação em uma única viagem, em um intervalo de tempo curtíssimo, a intensidade da luz crescerá até o limite permitido pela montagem experimental. 4

Essa visão de um único fóton gerando um feixe de luz potente em muito menos de um segundo capturou a imaginação de cientistas, militares e também do publico em geral na década de 1960, quando os primeiros lasers foram desenvolvidos. Armas laser se tornaram o raio mortal, a flecha de Apolo, favorito de escritores de ficção científica desde a década de 1960 , como pode ser visto pela sua presença no primeiro episódio de Star Trek (1965), na série perdidos no espaço (1965-1968) e no épico Star Wars.

Entretanto, é mais fácil falar do que fazer um sistema daqueles. Há dois problemas cruciais para montar aquele esquema descrito há pouco. O primeiro é que obter um meio onde quase todos os

\footnotetext{
${ }^{4}$ Uma simulação que ilustra essa descrição pode ser encontrada em https://phet.colorado.edu/en/simulation/lasers.
}

átomos estão no estado excitado não é uma tarefa fácil. Aquela situação é chamada de inversão de população, justamente porque, na natureza, a população de átomos no estado de menor energia é, como regra, maior que a população de átomos no estado de maior energia. Então, para produzir um laser, é necessário desenvolver uma forma eficiente de criar essa inversão de população artificial. Podemos compreender um pouco mais esse ponto fazendo uma analogia entre dinheiro e energia. Como sabem, a população de ricos é muito menor do que a de pobres. Para se inverter essa situação é necessário que os governos interfiram redistribuindo o dinheiro, o que, vocês podem imaginar, não é nada fácil.

O segundo grande problema é encontrar uma forma eficiente de confinar a radiação no sistema de forma a fazer com que ela percorra o meio várias vezes, estimulando quase todos os átomos excitados a emitir radiação. $\mathrm{O}$ aparato que faz isso é chamado de ressonador. No exemplo que vimos o ressonador é o par de espelhos paralelos. Para que esse sistema seja eficiente os espelhos precisam refletir praticamente $100 \%$ da luz e devem estar perfeitamente paralelos, alinhados. Uma pequena inclinação em um dos espelho e a luz é refletida para fora em poucas reflexões. A melhor forma de obter um alinhamento perfeito hoje em dia é utilizando um laser como nível, mas na época, obviamente, não dava para utilizar um laser para criar o primeiro laser.

Então, embora o princípio do laser pareça simples e hoje estes dois problemas sejam relativamente fáceis de solucionar, o conhecimento e tecnologia necessários para usar emissão estimulada para amplificar radiação amadureceu apenas após a Segunda Guerra Mundial, graças à guerra. A primeira pessoa a pensar em usar emissão estimulada para gerar luz foi um físico da União Soviética chamado Valentim Fabrikant no final da década de 1930, mas Fabrikant não conseguiu criar uma forma eficiente de obter uma inversão de população e não chegou a elaborar um ressonador. É muito pouco provável que qualquer outra pessoa pudesse ter obtido tal façanha naquela época, mesmo com o conhecimento e tecnologia mais avançados que se tinha até a Segunda Guerra [10]. Durante a guerra, físicos em vários países, mas especialmente nos Estados Unidos, Inglaterra, Alemanha e União Soviética se dedicaram com afinco à tarefa de desenvolver a tecnologia de rádio, tanto para comunicação quanto para empregála em radares que seriam utilizados para detectar 
aviões, navios e submarinos inimigos. As tarefas principais eram desenvolver as tecnologias de geração e deteç̧ão de ondas de rádio curtas. Os geradores precisavam ser mais estáveis, potentes e gerar ondas cada vez mais curtas, se aproximando do limite inferior da região chamada de micro-ondas (ondas com comprimentos de $30 \mathrm{~cm}$ a $1 \mathrm{~mm}$ ). Os fornos de microondas atuais também foram produtos da evolução dessa tecnologia. Trabalhando naquelas tarefas os físicos aprenderam a combinar seus conhecimentos teóricos de mecânica quântica com conhecimentos de engenharia e tecnologia de ponta em geração, estabilização e amplificação de micro-ondas [11].

Foi aquela combinação de conhecimentos de física e engenharia, associada às novas tecnologias de geração e detecção de micro-ondas, que permitiu físicos nos Estados Unidos e na União Soviética obterem sucesso no controle do efeito de emissão estimulada para amplificar radiação. O time norteamericano era composto pelo físico da Universidade de Colúmbia Charles Townes, seu estudante de doutorado, James Gordon, e um pós-doutorando, Herbert Zeiger (Figura 6). O time Soviético era inicialmente composto pelo físico Alexander Prokhorov e seu estudante de doutorado Nikolai Basov, que trabalhavam no Instituto de Física da Academia de Ciências da União Soviética (FIAN). Embora entre eles apenas Charles Townes tivesse trabalhado diretamente com radares, no pós-guerra habilidades técnicas de engenharia eram benquistas tanto nos Estados Unidos quanto na União Soviética. Os dois grupos eram muito bem familiarizados com a mais avançada tecnologia de micro-ondas em seus respectivos países e eram pioneiros em um novo campo de pesquisa chamado espectroscopia de micro-ondas, que usa radiação de micro-ondas para estudar a estrutura de moléculas e núcleos atômicos. Não foi por acaso que eles pensaram nas mesmas soluções para os problemas de obter inversão de população e de fazer um ressonador bom o bastante para fazer o ganho de energia superar as perdas $[12$.

Charles Townes teve a ideia de como obter inversão de população para fazer um gerador de microondas usando emissão espontânea na primavera (do hemisfério norte) de 1951, enquanto se preparava para uma reunião onde alguns bons físicos estadunidenses discutiriam formas alternativas de gerar micro-ondas curtas, que permitissem superar as limitações das formas existentes. Sua ideia inicial, rabiscada no fundo de um envelope, foi criar um

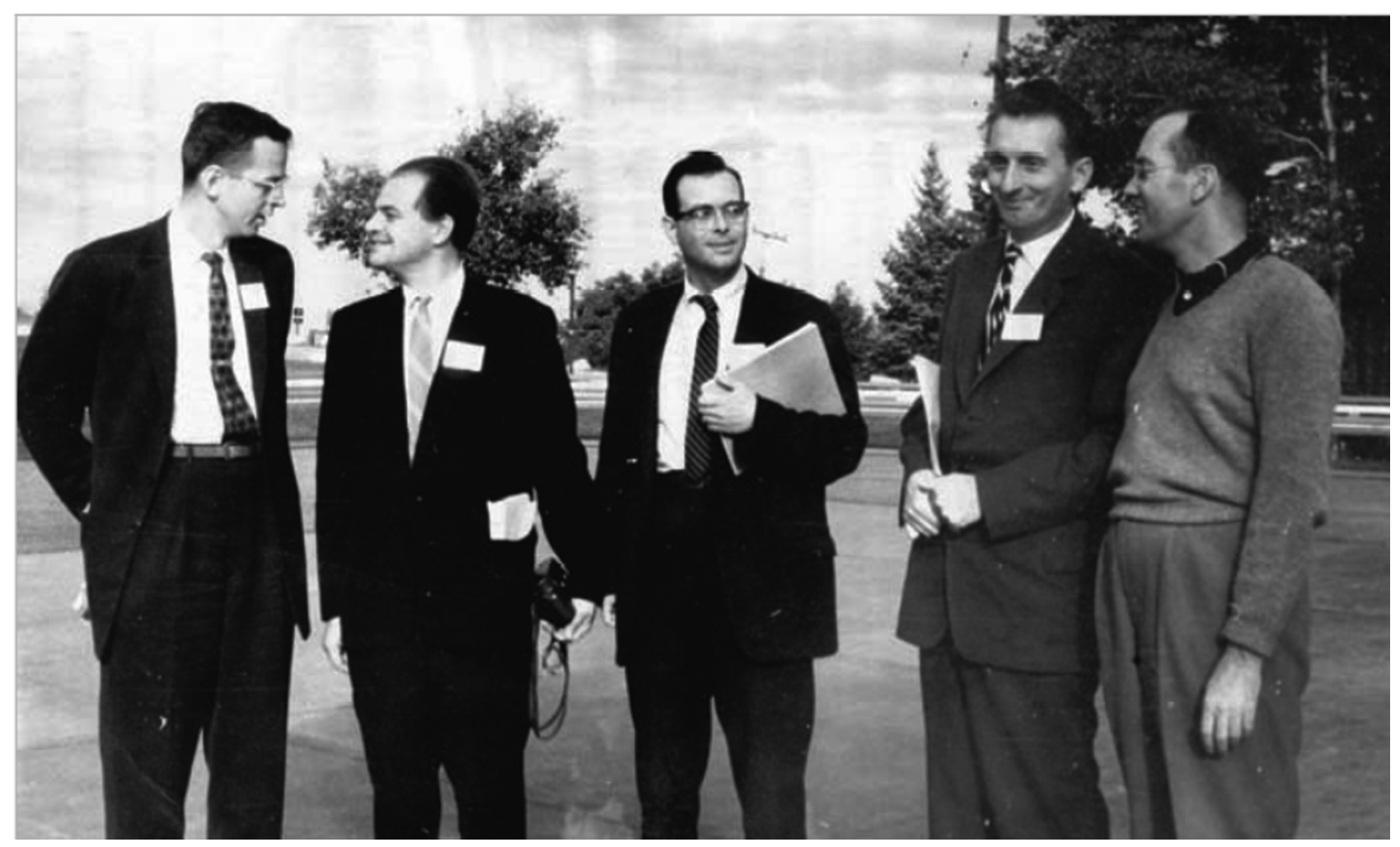

Figura 6: O primeiro encontro dos inventores do maser, EUA, 1959. Da esquerda para a direita: H. Zeiger, N. Basov, J. Gordon, A. M. Prokhorov e C. Townes. Foto cortesia de Alexander K. Prokhorov, neto de A. M. Prokhorov. 
feixe de moléculas de amônia no qual o número de moléculas nos estados excitado e fundamental era praticamente o mesmo e então separar as moléculas de acordo com seus estados de energia, usando um campo magnético não-uniforme. Quando passamos um feixe de moléculas por um campo magnético não uniforme, como o criado por esses ímãs, as moléculas que estão no estado excitado vão para um lado e as moléculas que estão no estado fundamental vão para o outro lado, ou seguem em linha reta. Isso é um efeito quântico que foi detectado pela primeira vez no famoso experimento de Stern-Gerlach. O importante aqui é entender que uma vez que as moléculas estão separadas, Townes pensou, ele poderia direcionar apenas as moléculas excitadas para a um ressonador. Isto lhe permitiria obter um meio no qual praticamente todas as moléculas estão excitadas, prontas para emitir radiação e mudar para o estado fundamental. Uma vez que as moléculas estão separadas, pode-se enviar apenas moléculas no estado de maior energia, ou estado excitado, para uma cavidade de microondas onde a radiação seria amplificada (Figura 7).

Os soviéticos tiveram basicamente a mesma ideia antes do final de 1952, a diferença foi que eles pensaram em usar um feixe de fluoreto de césio $(\mathrm{CsF})$ e um campo elétrico não uniforme, em vez de magnético, para separar as moléculas. Tanto os norte-americanos quanto os soviéticos entenderam desde o início que se as moléculas do feixe pudessem emitir espontaneamente enquanto estivessem passando pela cavidade, e se a cavidade fosse boa o bastante para reter boa parte da radiação, eles teriam um gerador de micro-ondas baseado em um princípio inteiramente original.

Entretanto, a implementação daquelas ideias não foi tão simples assim. Como Basov e Prokhorov compreenderam por meio de alguns cálculos, e os norte-americanos descobriram quando já estavam construindo o dispositivo, o tempo que as moléculas passavam dentro da cavidade era menor que o tempo de relaxação das moléculas, o que significa que as moléculas poderiam passar por toda a cavidade sem emitir radiação. Um outro problema que eles enfrentaram foi que a melhor cavidade que eles conseguiram fazer com a tecnologia disponível não era boa o bastante para confinar a parcela de radiação necessária para fazer um gerador. Felizmente, aqueles dois problemas tinham uma única solução: introduzir radiação na cavidade (Figura 8).

Introduzindo radiação na cavidade eles de uma vez só estimulariam as moléculas a emitir radiação e diminuiriam as exigências sobre a cavidade. O problema é que o dispositivo não seria mais um gerador, como eles queriam, mas um amplificador de microondas. Os soviéticos apresentaram aquela alternativa desde a primeira vez que eles discutiram suas ideias em público, para um público altamente seleto de cientistas que tinham licença para participar de uma reunião secreta onde estavam sendo discutidos trabalhos sigilosos, relevantes para a construção de bombas atômicas [14]. Os norte-americanos, de forma independente, depois de várias tentativas malsucedidas de construir um gerador baseado em emissão

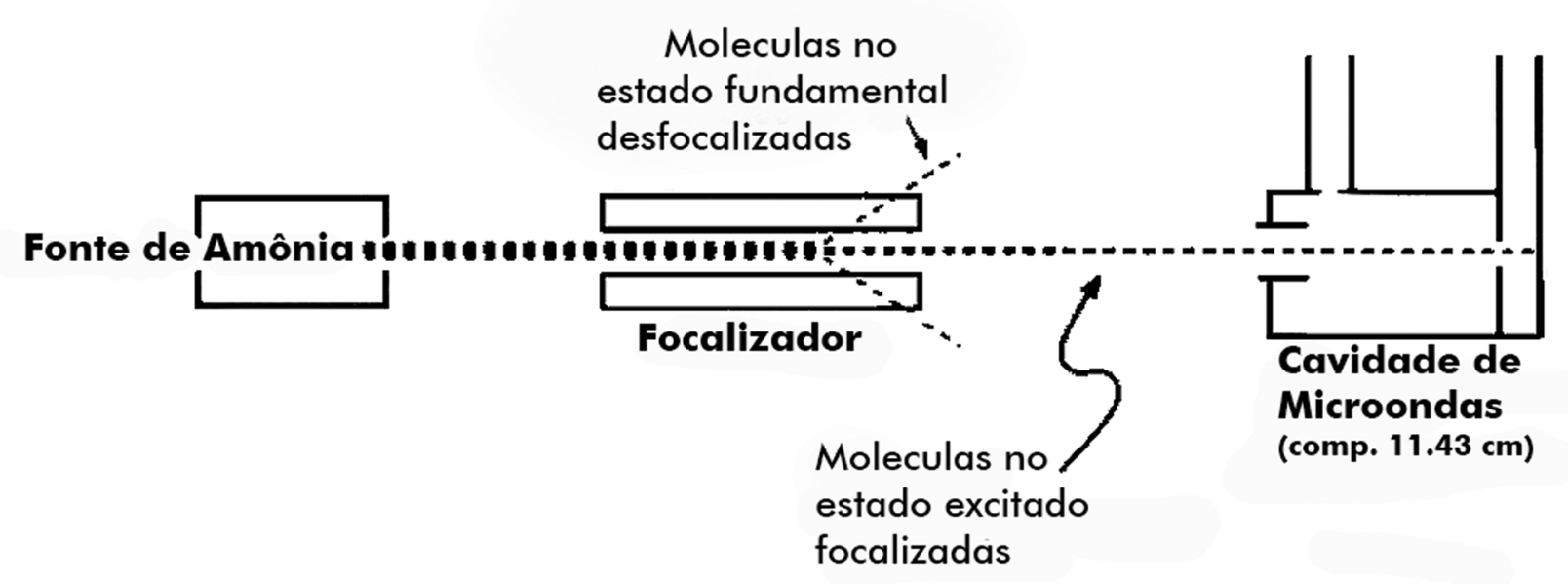

Figura 7: As moléculas que saem da fonte de amônia passam pelo focalizador que deflete as moléculas no estado de energia menor. Apenas as moléculas no estado de energia maior são direcionadas para a cavidade. Figura modificada a apartir de uma figura do livro The Laser in America de Joan Bromberg [13]. 


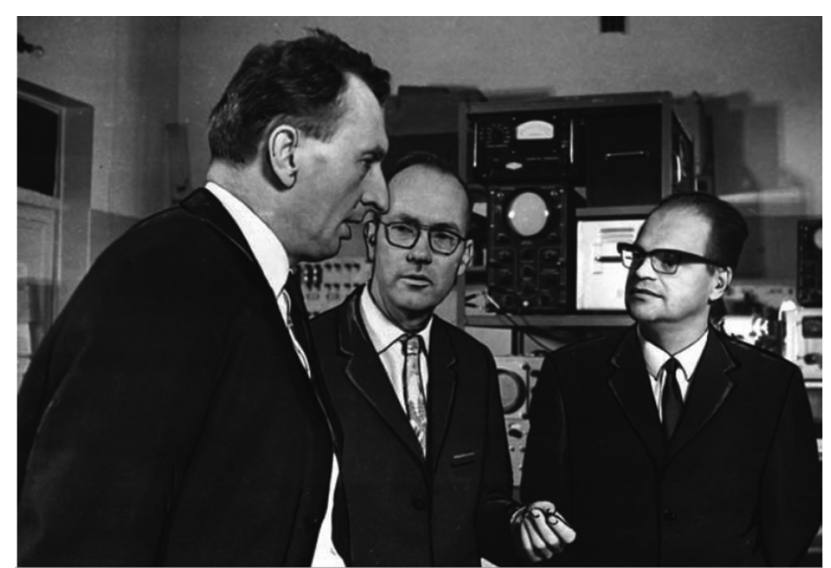

Figura 8: Alexander Prokhorov, Charles Townes and Nikolai Basov, no Instituto de física da Academia de Ciências da URSS, em Moscou, em 1965. Foto cortesia de Alexander K. Prokhorov

espontânea, no mesmo ano concluíram que teriam que introduzir radiação para estimular a emissão de mais radiação. Com aquela mudança eles conseguiram obter amplificação de radiação pela primeira vez em abril de 1954 e batizaram o dispositivo com a elegante sigla MASER (Microwave Amplification by Stimulated Emission of Radiation) 15.

Os soviéticos, que haviam começado fazendo cálculos teóricos, primeiro fizeram uma teoria detalhada do gerador molecular (como eles chamavam o maser inicialmente) e só depois é que eles começaram a construir o dispositivo [16]. Eles operaram um maser de amônia pela primeira vez na primeira metade de 1955 (Figura 9).

As primeiras análises daqueles masers revelaram que eles eram de fato dispositivos revolucionários. A estabilidade sem precedentes de suas frequências fizeram deles os relógios mais precisos e o nível baixíssimo de ruídos fizeram deles os amplificadores mais sensíveis inventados até então [17,18]. Entretanto, os primeiros masers eram grandes e difíceis de manejar e por isso encontraram poucas aplicações fora de laboratórios de pesquisas, todas elas militares. Nos anos subsequentes físicos nos Estados Unidos, União Soviética e em outros países se dedicaram à tarefa de tornar os masers mais manejáveis e capazes de amplificar radiação de outras frequências, incluindo nas frequências da luz visível, usando também materiais e efeitos diferentes para obter inversão de população 19.

Os físicos começaram a considerar seriamente a possibilidade de fazer um maser que amplificasse luz, ou seja, de fazer um laser, por volta de 1957.
No ano seguinte Charles Townes e seu colaborador Arthur Schawlow discutiram algumas possibilidades de criar o que eles chamaram de maser ótico em um artigo que se tornou um clássico da física de lasers e é considerado como o salvo que deu a largada da corrida para operar o primeiro laser 20 .

$\mathrm{O}$ vencedor da corrida foi um engenheiro norteamericano para quem ninguém dava nada-Theodore Maiman - na primavera de 1960. Maiman venceu a corrida com uma montagem surpreendentemente simples, feita de um bastão de rubi colocado no centro de uma lâmpada de flash (Figura 10). Ambos os lados do bastão foram cobertos cuidadosamente com camadas de prata, mas um dos lados foi deixado semi-transparente para que a radiação pudesse escapar 21.

O laser, no entanto, não foi uma invenção de um único homem, ou um único país, e a história do laser pode ser vista como uma competição transnacional entre homens comprometidos com ideologias opostas que resultou em um empreendimento coletivo para criar um dos dispositivos mais extraordinários já inventados.

Cientistas, naturalmente, competem entre si em ocasiões em que alguns grupos estão trabalhando no mesmo problema, mas no contexto da Guerra Fria a competição entre físicos norte-americanos e soviéticos adquiriu novas conotações. Ela tornou-se parte da corrida armamentista e foi também estimulada pela necessidade de mostrar a superioridade de um sistema político sobre o outro. Desta forma, masers e lasers foram desenvolvidos naqueles países com mais afinco não apenas porque eles tinham as maiores comunidades de físicos do mundo, mas também porque aqueles dispositivos foram de certa forma produtos do redirecionamento da física em direção ao desenvolvimento de tecnologias militares [11,19].

Físicos estadunidenses e soviéticos aprenderam rápido a explorar o contexto da Guerra Fria para avançar suas próprias agendas, que, diga-se de passagem, tinham grande intersecção com as agendas dos militares. Para conseguir financiamento militar, físicos prometeram que lasers poderiam ser a base para uma nova arma revolucionária que poderia destruir mísseis intercontinentais, carregados com bombas atômicas, antes que eles conseguissem chegar ao alvo. Tal sistema mudaria definitivamente o balanço de poder na Guerra Fria. Os físicos prometeram ainda que lasers poderiam também ser utilizados para desenvolver radares mais precisos, 


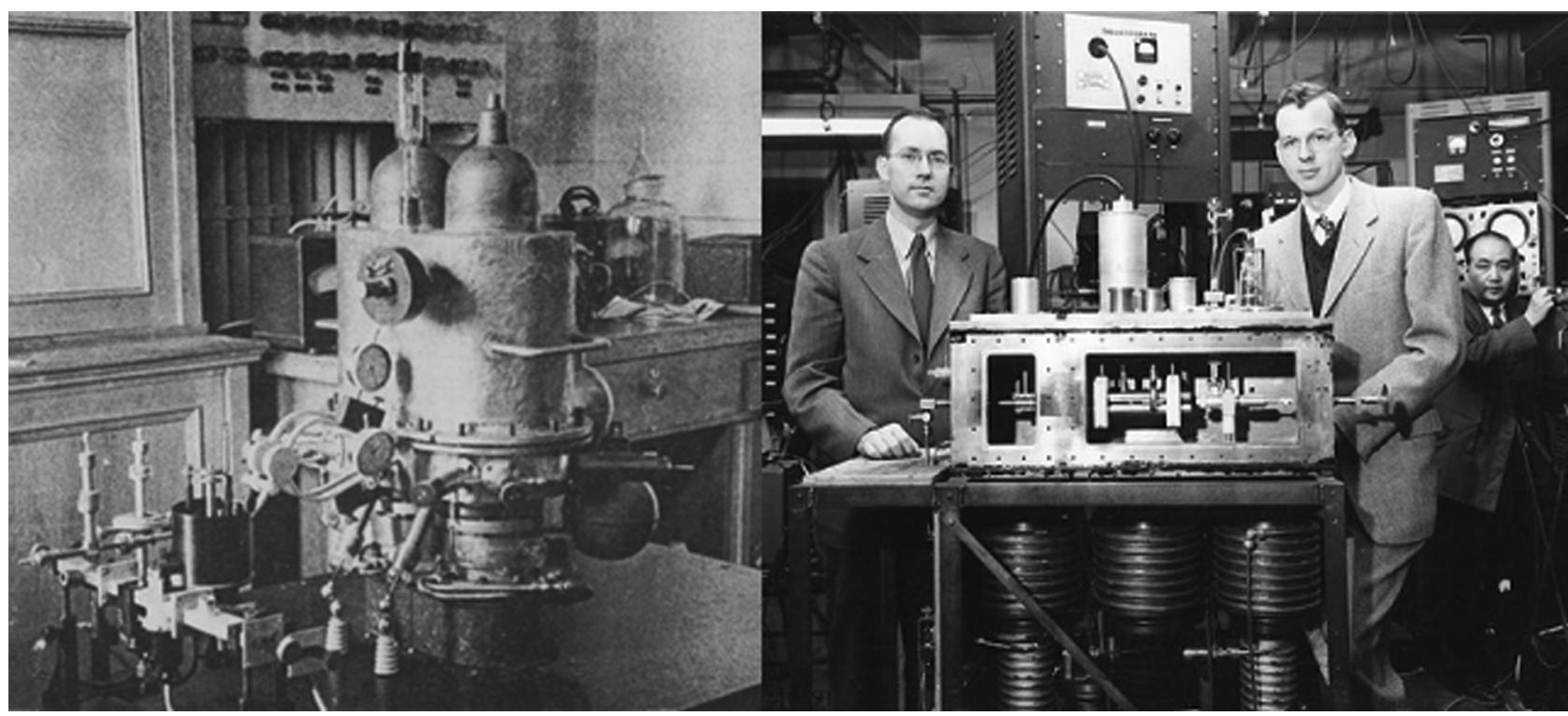

Figura 9: $\mathrm{Na}$ foto da esquerda, o primeiro maser soviético e na direita o primeiro maser estadunidense com Townes e Gordon posando para a foto divulgada pela assessoria de imprensa da Universidade de Columbia. Atrás está um técnico de laboratório T. Wang.

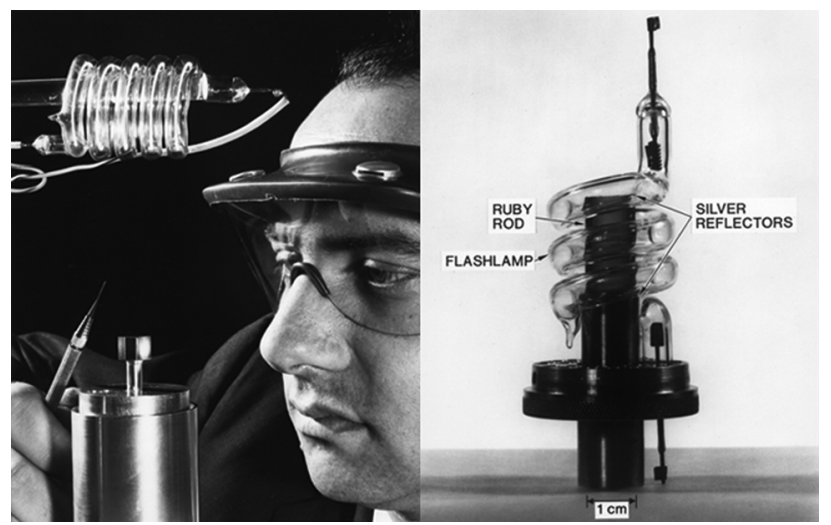

Figura 10: Na esquerda: Teodore Maiman olhando para um cilindro de ruby, o coração de seu laser. Foto de uma propaganda da Hughes Aircraft Co., empresa para a qual ele trebalhava, em julho de 1960. Na direita: o primeiro laser, inventado por T. Maiman, foi uma simples montagem de um bastão de rubi no centro de uma lâpada de flash. Fonte: AIP.org.

separar isótopos, e poderiam ser até mesmo a chave para dominar a cobiçada tecnologia de fusão nuclear 22]. Como consequência de tantas promessas audaciosas, nos três anos que se seguiram à invenção do laser, só o Departamento de Defesa dos Estados Unidos investiu 220 milhões de dólares (atualizando os valores para 2015, o que, na cotação junho de 2016, seria equivalente a mais de 760 milhões de reais) [23, p. 179]. E o Departamento de Defesa não era a única agência militar financiando pesquisa científica nos Estados Unidos. Os físicos soviéticos argumentam que a União Soviética investiu ainda mais que os Estados Unidos para desenvolver lasers na década de 1960 24.

Aquele padrão, no entanto, não ficou restrito às superpotências da Guerra Fria. Em 1960 um físico brasileiro chamado Sérgio Porto mudou-se para os Estados Unidos para fazer uma carreira de sucesso, trabalhando com lasers, que começou nos Laboratórios da Bell, na época a maior empresa telefônica dos EUA, que investia pesadamente no desenvolvimento de novas tecnologias. No final da década o governo militar que havia se instaurado aqui no Brasil iniciou uma negociação para trazer Sérgio Porto de volta ao Brasil com o intuito de desenvolver um método de separação de isótopos, para enriquecer urânio, baseado em lasers. Aquele foi um passo em direção ao domínio da tecnologia de enriquecimento de urânio, um elemento radioativo que, uma vez enriquecido, pode ser usado tanto para gerar energia nuclear, quanto para produzir uma bomba atômica. Nos termos do acordo fechado entre Porto e o regime militar, Porto recebeu um laboratório de última geração, um time de 30 doutores, formado majoritariamente por seus colaboradores nos Estados Unidos, e dois milhões de dólares da época, que, fazendo as correções, valiam o equivalente a mais de 12 milhões de dólares atualmente, ou 45 milhões de reais! Um investimento impressionante para os padrões brasileiros na época. Embora, até onde sa- 
bemos, o grupo de Sérgio Porto tenha falhado em sua missão principal - desenvolver um método de separação isotópica baseado no laser- ele desenvolveu uma série de aplicações tecnológicas de lasers em medicina que permitiu o Brasil se tornar um líder mundial em aplicações médicas de lasers 25$]$.

Como a física nuclear, podemos dizer que a física de laser avançou durante a Guerra Fria por conta de seu potencial para aplicações militares. No entanto, diferentemente da bomba atômica, que se tornou um símbolo da capacidade do homem se se autodestruir, lasers encontraram sobretudo aplicações pacíficas. Com os CDs, os lasers trouxeram música para nossos lares; com suas muitas aplicações médicas, lasers têm melhorado a qualidade de vida de milhões de pessoas; com comunicações de fibras óticas, lasers conectaram boa parte do mundo em altíssimas velocidades. As numerosas aplicações industriais de lasers, como o corte e fortalecimento de metais, por exemplo, diminuíram os custos e aumentaram a qualidade da produção. Em suma, lasers transformaram nossa sociedade. De fato, um presente divino.

\section{Referências}

[1] V. Jardim e J. Barros, Caderno Brasileiro de Ensino de Física 16, 154 (1999).

[2] E. Valadares e A. Moreira, Caderno Brasileiro de Ensino de Física 21, 359 (2004).

[3] E.S. Teixeira, O. Freire Jr. e C.N. El-Hani, Ciência \& Educação 15, 529 (2009).

[4] Brasil, Nacional Comum Curricular - Proposta Preliminar - Segunda versão revista (MEC, Brasília, 2016).

[5] D.J. Kevles, Isis 62, 47 (1971).

[6] P. Forman, Cadernos de Historia e Filosofia da Ciência Suplemento, 3 (1983).

[7] P. Forman, Isis 64, 150 (1973).

[8] A. Bagdonas, J. Zanetic e I. Gurgel, Revista Brasileira de História da Ciência 7, 242 (2014).

[9] A. Einstein, Physikalische Zeitschrift, 18, 121 (1917).

[10] Svetlana G. Lukishova, Journal of the European Optical Society: Rapid Publications 5:10045s (2010).

[11] P. Forman, Reviews of Modern Physics 67, 397 (1995).

[12] C.P. Silva Neto, Red Descendants of Apollo: The Making of Soviet Laser Physics. PhD Thesis, Universidade Federal da Bahia/Universidade Estadual de Feira de Santana (2015).

[13] J.L. Bromberg, The Laser in America, 1950-1970 (MIT Press, Cambridge, (1991).

[14] N.G. Basov, in: Zapiski arkhivariusa (FIAN, Moskva, 1953).
[15] P. Forman, Osiris 7, 105 (1992).

[16] N.G. Basov e A.M. Prokhorov, Doklady Akademii Nauk SSSR 101, 47 (1955).

[17] N.G. Basov, Molekuliarnyi Generator. Avtoreferat dissertatsii, Fizicheskii institut imeni P. N. Lebedeva, (1956).

[18] J.P. Gordon, H.J. Zeiger, and Charles H. Townes, Physical Review 99, 1264 (1955).

[19] P. Forman, in: National Military Establishments and the Advancement of Science and Technology, edited by Paul Forman and J.M. Sanchez-Ron (Springer, Dordrecht, 1996), p. 261-326.

[20] A.L. Schawlow and C.H. Townes, Physical Review 112, 1940 (1958).

[21] T.H. Maiman, Nature 187, 493 (1960).

[22] J. Hecht, Beam: The Race to Make the Laser (Oxford University Press, New York, 2005).

[23] I. Hacking, The Social Construction of What? (Harvard University Press, Cambridge, 1999).

[24] P. Forman, Studies in the Physical and Biological Sciences 18, 149 (1987).

[25] W.A.L. de Santana and O. Freire Jr., Revista Brasileira de Ensino de Física 32, 3601 (2010). 